\section{Spectacular Circumhorizontal Arc over Austin, Tex.}

Kenneth H. Jehn and Keith Zimmermann, Atmospheric Science Group, University of Texas, Austin, Tex. 78712

According to Fraser (1975), the circumhorizontal arc is a "rare spectacle" (p. 240) and "one of the most beautiful of all the halos" (p. 239). The brilliant beauty of the very rare halo displays often lasts only a few minutes. However, a spectacular circumhorizontal arc was displayed over Austin, Tex., for $\sim 2 \mathrm{~h}$ on 24 April 1977. The brightly colored arc appeared at $\sim 1130 \mathrm{CDT}$. Later, when the arc had almost faded from view, a nearly complete $22^{\circ}$ halo appeared. Thousands of central Texas residents observed the display, and local radio stations reported the event.

Gene Beard, a neighbor of one of the authors $(\mathrm{KHJ})$, first saw the arc appear a little before 1130 CDT and inquired about it. The arc was initially centered over the southeast horizon and extended $\sim 90^{\circ}$ in azimuth. The brightly colored band, with red uppermost, was $\sim 3^{\circ}$ wide and showed a beautiful spectral separation.

The display was made even more spectacular by the passage of altocumulus billows (see Fig. 1). These wavetype clouds passed rapidly from west-northwest to east-

0003-0007/78/0170-0171\$05.00

(C) 1978 American Meteorological Society southeast. According to A. B. Fraser (personal communication, 1977), the altocumulus clouds were passing above the ice crystals forming the arc. In the figure, a shadow from the center billow is clearly evident on the color band. In addition, one can see the red colors reappearing on the trailing edge of the center billow. Apparently the ice crystals were falling a considerable distance from the cirrus layer (reported to be at $6100 \mathrm{~m}$ ) to a level below the altocumulus clouds at $\sim 4300 \mathrm{~m}$.

During the passage of the altocumulus clouds, the colors of the arc appeared to be enhanced between the cloud elements. Moreover, there seemed to be a distortion of the colored band into arc shapes concave upward. Fraser (personal communication, 1977) has stated

... that the streamers of ice crystals appear concave upwards is certainly correct, however it is doubtful that the arc itself does. In fact, if one assumes that the crystals might be tipped by the acceleration of the curved flow field, then the arc should be curved the other way.

After a group of altocumulus billows had passed, the circumhorizontal arc became much less spectacular. On one occasion, it nearly faded from sight. Then, another group of billows would appear, and the increased brilliance of the arc colors could be observed again.

After $\sim 2 \mathrm{~h}(\sim 1330 \mathrm{CDT})$, the circumhorizontal arc was beginning to fade. The colored bands had moved with the sun to a position closer to due south. At about this time, a nearly complete $22^{\circ}$ halo formed. For a

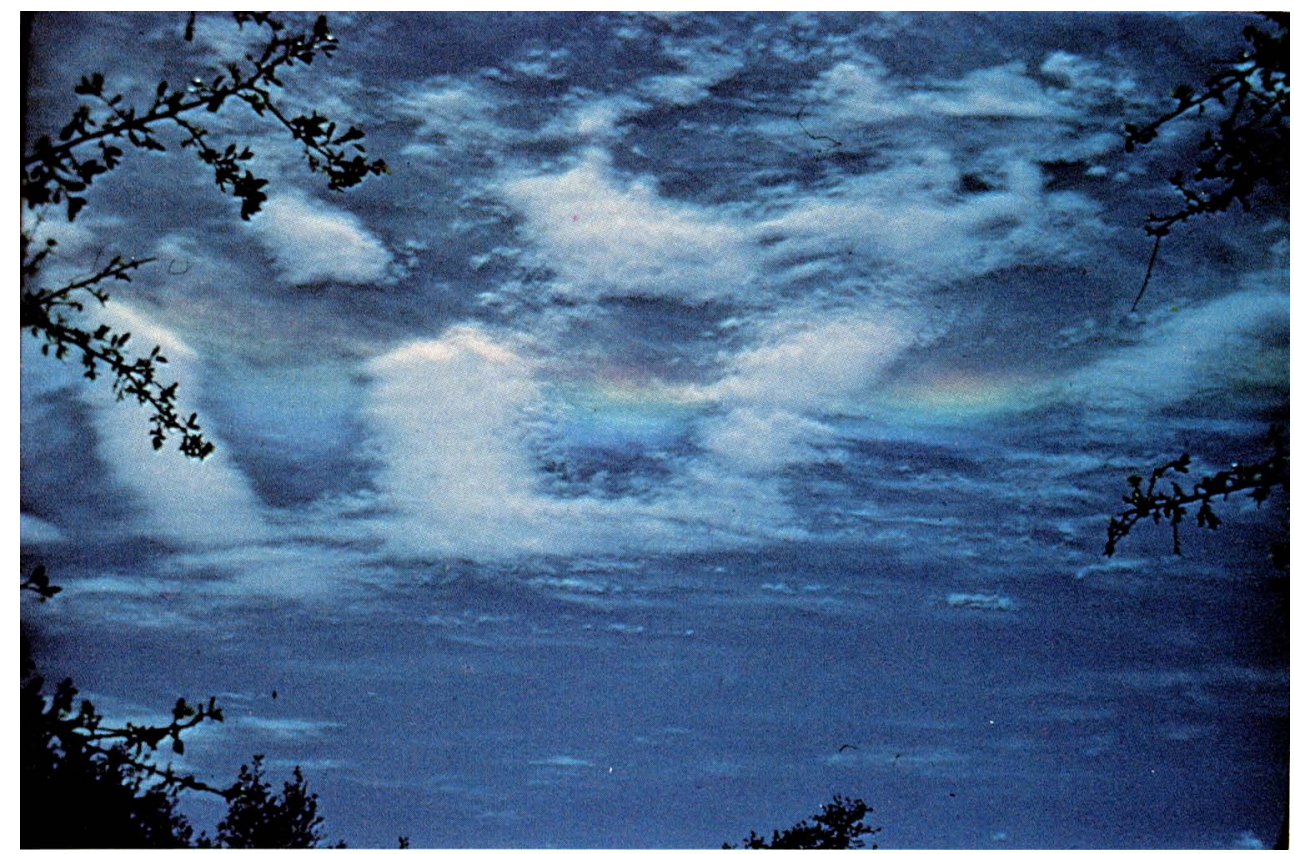

Fig. 1. Rare circumhorizontal arc made even more spectacular by the passage of altocumulus billows, Austin, Tex., 24 April 1977. (Photo by Prof. Kenneth H. Jehn.) 
brief period, both halo phenomena were visible simultaneously, although the arc was very faint. A few minutes later, only the $22^{\circ}$ halo was observed. Although it was a complete ring, the colors were brighter on the south portions than elsewhere.

At the latitude of Austin $\left(30^{\circ} 18^{\prime} \mathrm{N}\right)$ the sun's altitude on 24 April was $72^{\circ} 30^{\prime}$ at solar noon (1329 CDT). The "best" time for viewing the circumhorizontal arc would have been $\sim 1 \mathrm{~h}$ earlier. At this time, the solar altitude was $68^{\circ}$, corresponding to minimum deviation of the refracted solar beam in horizontal ice plates. Two hours earlier, the solar altitude was computed to be $57.3^{\circ}$. The phenomenon could not have been observed prior to that time since $57^{\circ} 48^{\prime}$ is the minimum solar altitude at which the circumhorizontal arc can be observed (Humphreys, 1964, p. 532).

After $1330 \mathrm{CDT}$, when the $22^{\circ}$ halo appeared, the ice crystal population must have changed so that hexagonal columns with long axis horizontal were dominant. The minimum solar altitude was computed to occur again near 1530 CDT, after which the circumhorizontal arc could not have been observed, even with the proper ice crystal forms. The arc never appeared again after it faded from view with the advent of the $22^{\circ}$ halo at $\sim 1330$ CDT.

The photograph in Fig. 1 was taken by the senior author (KHJ). A $35 \mathrm{~mm}$ camera with a $50 \mathrm{~mm}$ focal length lens was used with Kodachrome 25 film. The display was also observed and photographed by Dr. Norman K. Wagner, Associate Professor of Meteorology, and by the coauthor (KZ) and Eduardo Bosch, graduate students.

Acknowledgments. The authors are indebted to Professor Fraser of Pennsylvania State University for his helpful comments on the photographs and manuscript, to graduate student Alfred J. Garrett for initial calculations of solar altitude, and to senior meteorology student Charles Meyers for his help in interpreting the photographs.

\section{References}

Fraser, A. B., 1975: Meteorological optics. The Atmosphere, chapt. 9, by R. A. Anthes et al., Charles E. Merrill, Columbus, Ohio, $339 \mathrm{pp}$.

Humphreys, W. J., 1964: Physics of the Air. Dover, N.Y., $676 \mathrm{pp}$. announcements continued from page 160

\section{Quality Assurance in Air Pollution Measurement- Call for papers}

The Air Pollution Control Association (APCA) and the American Society for Quality Control are soliciting papers for a jointly sponsored specialty conference entitled, "Quality Assurance in Air Pollution Measurement." The conference will be held in New Orleans, La., 12-13 March 1979. Sessions will include presentations in the following topical areas: 1) Standardizing Quality Assurance Methods; 2) Quality Assurance Program Management and State and Local Agency Implementation; 3) Scientific and Legal Problems of Measurement Uncertainty; 4) Statistical Analysis of Ambient Air Quality and Trend Data; 5) Quality Assurance in Meteorological Monitoring and Analysis; 6) Quality Assurance in Monitoring Network Design and Siting; 7) Screening of Ambient Air Quality Data; and 8) Monitoring Systems and Traceability. All papers offered for presentation must be new contributions in the air pollution and quality assurance fields. An abstract of 500 words and brief biographical sketch should be submitted no later than 30 April 1978 to: Robert C. Beebe (APCA Cochairman), Supervisor, Data Management Section, Data Services Branch, TVA-346 Evans Bldg., Knoxville, Tenn. 37902.

\section{U.S. antarctic research program- Request for proposals}

The National Science Foundation (NSF) anticipates the availability of $\$ 6$ million in fiscal year 1979 for research in Antarctica and its environs, or for antarctic related research at U.S. institutions. Most of the logistics and support require- ments for investigators in the field will be provided separately by NSF. Investigators wishing to perform antarctic research should submit proposals in collaboration with their institutions according to the NSF's booklet, Grants for Scientific Research (NSF-76-38, available from NSF, Washington, D.C. 20550).

The deadline for unsolicited proposals is 1 June 1978. Proposals received by the deadline and approved for award will be provided funds for performance periods as follows:

1) for research in Antarctica: the 1979-80 austral summer season, extending through the Southern Hemisphere summer of 1980 if appropriate;

2) for research or data analysis in the United States, commencing approximately 1 January 1979.

The research program is designed to foster research on problems of worldwide and regional scope, including environmental monitoring and resources research. Investigators may propose to perform research and analysis individually, in small teams, or in large interdisciplinary projects. Proposals for research in glaciology, biology, earth sciences, upper atmosphere physics, meteorology, and the ocean sciences will be accepted. The announcement of the program details the objectives held for each field; a copy is available from Division of Polar Programs, National Science Foundation, Washington, D.C. 20550.

NSF will also accept applications for an exchange scientist from the United States for a year of research at one of the U.S.S.R. research stations in Antarctica. Before submitting a formal proposal, however, those interested in this program are encouraged to contact the project officer (tel: 202-6324078).

Continued on page 174 